Pawel GIL ${ }^{1}$

Joanna WILK ${ }^{2}$

\title{
INSTALACJA CHP Z SILNIKIEM SPALINOWYM ZASILANYM GAZEM DRZEWNYM
}

\begin{abstract}
Artykuł zawiera opis koncepcji kogeneratora z silnikiem spalinowym czterosuwowym iskrowym zasilanym gazem drzewnym, pochodzącym ze zgazowania biomasy. Przedstawiono metody adaptacji silników spalinowych z zapłonem iskrowym oraz zapłonem samoczynnym do wykorzystania gazu drzewnego. Zaprezentowano problemy techniczne silników zasilanych gazem drzewnym.
\end{abstract}

Słowa kluczowe: zgazowanie biomasy, CHP, skojarzone wytwarzanie energii elektrycznej i ciepła, oczyszczanie gazu drzewnego

\section{Wstęp}

Zastosowanie gazu drzewnego w przemyśle motoryzacyjnym było możliwe już w latach 20. XX w. W 1923 roku francuski inżynier Jerzy Imbert (1884-1950) wynalazł generator gazu drzewnego do zastosowań w przemyśle motoryzacyjnym [11]. Generator Imberta zaczęto produkować na masową skalę od 1931 r. Pod koniec lat 30. XX w. wyprodukowano ok. 9000 pojazdów zasilanych gazem drzewnym, głównie w Europie [11]. W późniejszych latach masową produkcję samochodów z tą technologią kontynuowali: Ford, General Motors, Mercedes-Benz. Masowo wykonywano również generatory gazu drzewnego domowym sposobem, z elementów pralek, zbiorników czy butli [10].

Podczas II wojny światowej zużycie benzyny na potrzeby prowadzenia działań wojennych było wysokie, zwłaszcza w lotnictwie. Rezerwując benzynę dla lotnictwa, samochody osobowe i dostawcze zasilano gazem drzewnym (niem. holzgas). Liczbę samochodów zasilanych gazem drzewnym podczas II wojny szacuje się na $7 \mathrm{mln}$ [12]. Dostępność benzyny pod koniec lat 40. skutkowała szybkim wyparciem technologii Imberta $\mathrm{z}$ zastosowań w pojazdach. Było to spowodowane niską sprawnością, niewygodną obsługą i zagrożeniem życia (zatrucie tlenkiem węgla) [10]. Później gaz drzewny zaczęto stosować w stacjonarnych systemach CHP (ang. combined heat and power) [8].

\footnotetext{
${ }^{1}$ Autor do korespondencji/corresponding author: Paweł Gil, Politechnika Rzeszowska, tel.: (17) 8651288, e-mail: gilpawel@prz.edu.pl.

2 Joanna Wilk, Politechnika Rzeszowska, e-mail: joanwilk@ prz.edu.pl.
} 
Układy CHP zasilane gazem drzewnym mogą wykorzystywać różne technologie, takie jak: silnik spalinowy tłokowy o zapłonie iskrowym lub samoczynnym, turbina gazowa, turbina parowa, cykl Rankine'a, silnik Stirlinga lub ogniwo paliwowe. W dalszej części artykułu zaprezentowano przykłady pracujących instalacji zasilanych gazem drzewnym, o różnych mocach elektrycznych, wykorzystujących różne technologie. W Danii pracowała stacjonarna instalacja Viking zasilana gazem drzewnym. Jest to system skojarzonego wytwarzania energii cieplnej i elektrycznej z biomasy [1]. W latach 2002-2006 przepracował on łącznie 3600 godzin. Instalację Viking charakteryzowała moc elektryczna $17,5 \mathrm{~W}$, moc cieplna $39 \mathrm{~W}$, przy mocy chemicznej paliwa równej $70 \mathrm{~W}$. Sprawność przetwarzania energii biomasy na energię elektryczną wynosiła $25 \%$. Silnik Deutz o pojemności 3,1 litra z zapłonem iskrowym był zasilany gazem drzewnym, ale dodatkowo posiadał doprowadzenie gazu ziemnego, używanego do rozruchu instalacji. Silnik spalinowy był połączony sprzęgłem z prądnicą elektryczną. Wykorzystany generator gazu drzewnego stanowił dolnociągowy reaktor zgazowujący zrębki drzewne, wykorzystujący powietrze jako czynnik gazyfikujący. Wartość opałowa gazu wyprodukowanego w generatorze wynosiła $6 \mathrm{MJ} / \mathrm{m}_{\mathrm{n}}{ }^{3}$ (normalnych metrów sześciennych), natomiast mieszanki dostarczanej do cylindrów silnika spalinowego $-2,6 \mathrm{MJ} / \mathrm{m}_{\mathrm{n}}{ }^{3}$ [1]. W Güssing w Austrii badano stacjonarną instalację CHP z generatorem gazu drzewnego w złożu fluidalnym. Instalację uruchomiono w 2001 r. [19]. Zgazowywarka wykorzystująca parę wodną jako czynnik gazyfikujący przekształcała odpady drzewne w gaz drzewny o wartości opałowej ok. $12 \mathrm{MJ} / \mathrm{m}_{\mathrm{n}}{ }^{3}$. Po dwustopniowym oczyszczeniu gaz był dostarczany do silnika spalinowego, który napędzał generator prądu dostarczający prąd do sieci elektroenergetycznej. Energia chemiczna paliwa poddawanego zgazowaniu wynosiła $8 \mathrm{MW}$, natomiast moc elektryczna prądnicy 2 MW. Sprawność elektryczną instalacji określono na 25\% przy uzyskanej mocy cieplnej 4,5 MW [19].

W pracy [13] zaprezentowano testową instalację pracującą w Danii, uruchomioną w 2001 r. Zastosowano silnik Stirlinga do współpracy z gazem drzewnym. Komora spalania oraz gorący wymiennik silnika Stirlinga zostały przystosowane do wykorzystania nieoczyszczonego gazu drzewnego zawierającego dziegieć oraz pył. Wykorzystano górnociągowy generator gazu drzewnego. System ma moc elektryczną $36 \mathrm{~kW}$. Moc chemiczna paliwa dostarczana w formie rozdrobnionego drewna wynosi $200 \mathrm{~kW}$. Dodatkowo instalacja jest chłodzona wodą wykorzystywaną do celów przemysłowych. Temperatura wody wlotowej wynosi $25^{\circ} \mathrm{C}$, natomiast wylotowej $40^{\circ} \mathrm{C}$. Moc cieplna odebrana to 130 kW. System CHP przepracował łącznie 350 godzin. Sprawność wytwarzania energii elektrycznej wynosiła 18\%, sprawność całkowita $83 \%$.

$\mathrm{W}$ pracy [16] zaprezentowano parametry silnika spalinowego o zapłonie iskrowym, zasilanego w 100\% gazem drzewnym w zmiennych warunkach pracy. Silnik spalinowy został połączony z generatorem prądu o mocy $75 \mathrm{~kW}$. Gaz drzewny o wartości opałowej wynoszącej $5,6 \mathrm{MJ} / \mathrm{m}_{\mathrm{n}}{ }^{3}$ był produkowany w gene- 
ratorze dolnociągowym. Jego skład to: $23 \%$ wodoru, $21 \%$ tlenku węgla, $0,9 \%$ metanu oraz dwutlenek węgla i azot. Sprawność elektryczna wynosiła $21 \%$.

\section{Generator gazu drzewnego}

Prototypowy generator gazu drzewnego zbudowany i uruchomiony w Katedrze Termodynamiki i Mechaniki Płynów Politechniki Rzeszowskiej jest urządzeniem małej mocy. Moc chemiczna dostarczanego paliwa wynosi ok. $20 \mathrm{~kW}$ [5]. W skład prototypowego generatora gazu wchodzą następujące urządzenia: płomienica, odpylacz inercyjny, chłodnica wodna, filtr z wkładem z wełny mineralnej oraz dmuchawa (rys. 1.). Wszystkie elementy są połączone ze sobą szeregowo, a instalacja jest hermetyczna. Proces zgazowania jest prowadzony przy podciśnieniu. Opracowany generator stanowi jednostkę współprądową - biomasa oraz czynnik zgazowujący poruszają się w tym samym kierunku (generator dolnociągowy). Jako medium zgazowujące wykorzystuje się powietrze. Zaletą takiego generatora jest możliwość uzyskania wysokiej temperatury w strefie spalania, co umożliwia wytworzenie gazu o niskiej zawartości dziegciu. Wadą jest natomiast konieczność stosowania odpowiednio rozdrobnionego paliwa. Generator jest autotermiczny - ciepło potrzebne do zapewnienia przebiegu reakcji endotermicznych wytwarza się w procesach częściowego utleniania paliwa biomasowego. Wartość opałowa gazu drzewnego wyprodukowanego w generatorze zależy od rodzaju zastosowanej biomasy, jej wilgotności, temperatury zgazowania, ciśnienia oraz medium zgazowującego (tab. 1.) [2,7]. Stosowanie powietrza do zgazowania biomasy powoduje rozcieńczenie azotem wytwarzanego gazu drzewnego, na skutek czego pogarsza się jego wartość opałowa (tab. 2.). Udział objętościowy azotu w gazie drzewnym wynosi wówczas 40-60\%. Zgazowanie biomasy tlenem lub parą wodną podwyższa wartość opałową gazu drzewnego, jednak technologia taka znacznie podnosi koszty inwestycyjne i eksploatacyjne generatora.

Rys. 1. Prototypowy generator gazu drzewnego

Fig. 1. Prototype of wood gas generator

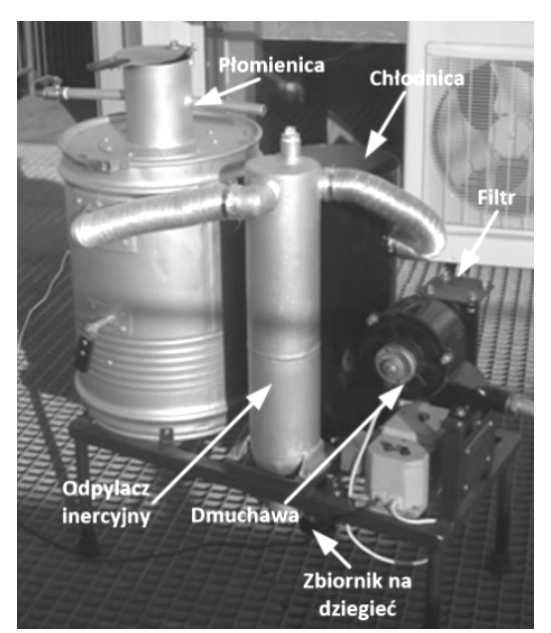


Tabela 1. Wpływ czynnika zgazowującego na wartość opałową gazu drzewnego (na podstawie [2])

Table 1. Influence of gasification medium on calorific value of wood gas (on the basis of [2])

\begin{tabular}{|l|c|}
\hline \multicolumn{1}{|c|}{ Medium zgazowujące } & Wartość opałowa gazu, $\mathrm{MJ} / \mathrm{m}_{\mathrm{n}}{ }^{3}$ \\
\hline Powietrze & $4-7$ \\
\hline Tlen & $10-18$ \\
\hline Para wodna & $12-28$ \\
\hline
\end{tabular}

Tabela 2. Typowy skład gazu drzewnego, zgazowanie powietrzem, ciśnienie atmosferyczne (na podstawie [14])

Table 2. Typical wood gas composition, gasification in air, atmospheric pressure (on the basis of [14])

\begin{tabular}{|c|c|c|c|c|c|}
\hline $\mathrm{Gaz}$ & $\mathrm{CO}_{2}$ & $\mathrm{CO}$ & $\mathrm{H}_{2}$ & $\mathrm{CH}_{4}$ & $\mathrm{~N}_{2}+\mathrm{O}_{2}$ \\
\hline$\%$ obj. & $14-17$ & $13-15$ & $12-14$ & $1,5-6$ & reszta \\
\hline
\end{tabular}

\section{Spalanie gazu drzewnego w tłokowym silniku spalinowym}

Spalanie gazu drzewnego w silnikach tłokowych jest możliwe zarówno w silnikach o zapłonie iskrowym, jak i zapłonie samoczynnym. W przypadku stosowania silników Diesla należy zastosować świecę zapłonową lub dodać do mieszanki gazu drzewnego olej napędowy. W takim rozwiązaniu olej napędowy jest wtryskiwany w minimalnych dawkach umożliwiających zainicjowanie procesu spalania. Gaz drzewny posiada niższą temperaturę spalania niż paliwa konwencjonalne, wynoszącą $1800 \mathrm{~K}$ (np. gaz ziemny $2210 \mathrm{~K}$ ). Przejawia się to niższym ciśnieniem spalania, które powoduje zmniejszenie momentu obrotowego [1]. Obniżenie mocy silnika spalinowego jest wynikiem dwóch efektów: niższej temperatury spalania oraz niższej wartości opałowej mieszanki. Rozpatrując wartość opałową gazu ziemnego $\left(36 \mathrm{MJ} / \mathrm{m}_{\mathrm{n}}{ }^{3}\right)$ oraz gazu drzewnego $\left(4,4 \mathrm{MJ} / \mathrm{m}_{\mathrm{n}}{ }^{3}\right)$, można dojść do wniosku, że zastosowanie gazu drzewnego przyczyni się do bardzo dużego zmniejszenia mocy silnika. Gaz drzewny jest dobrym paliwem dla silników spalinowych, ale powoduje zmniejszenie mocy o ok. 26\%. Wynika to $\mathrm{z}$ niskiego zapotrzebowania na powietrze do spalania, wynoszącego $1,3 \mathrm{~m}^{3}$ powietrza na $1 \mathrm{~m}^{3}$ gazu drzewnego [3]. Porównanie wartości opałowych mieszanki paliwowo-powietrznej dostarczanej do silnika zaprezentowano w tab. 3 .

Gaz drzewny mimo stosowania różnego rodzaju cyklonów, filtrów oraz skruberów nadal zawiera substancje smoliste oraz pył. Na rysunku 2. zaprezentowano test filtru na gazie wypływającym z dyszy. Wypływający gaz drzewny jest już za odpylaczem oraz filtrem $z$ wełny mineralnej. System oczyszczania gazu nie spełnia swojej roli. Na rysunku widać dużą ilość pyłu oraz dziegciu zatrzymanego na filtrze. Wytworzona w procesie substancja smolista oraz pył 
Tabela 3. Porównanie gazów do zasilania silników spalinowych (na podstawie [3])

Table 3. Comparison of gases used to power combustion engines (on the basis of [3])

\begin{tabular}{|c|c|c|}
\hline Nazwa & $\begin{array}{c}\text { Wartość opałowa, } \\
\mathrm{MJ} / \mathrm{m}_{\mathrm{n}}{ }^{3}\end{array}$ & $\begin{array}{c}\text { Wartość opałowa mieszanki } \\
\text { paliwowo-powietrznej, } \mathrm{MJ} / \mathrm{m}_{\mathrm{n}}{ }^{3}\end{array}$ \\
\hline Gaz ziemny & 36 & 3,32 \\
\hline Gaz drzewny, medium powietrze & 4,4 & 2,22 \\
\hline Gaz drzewny, medium para wodna & 10,9 & 3,10 \\
\hline
\end{tabular}

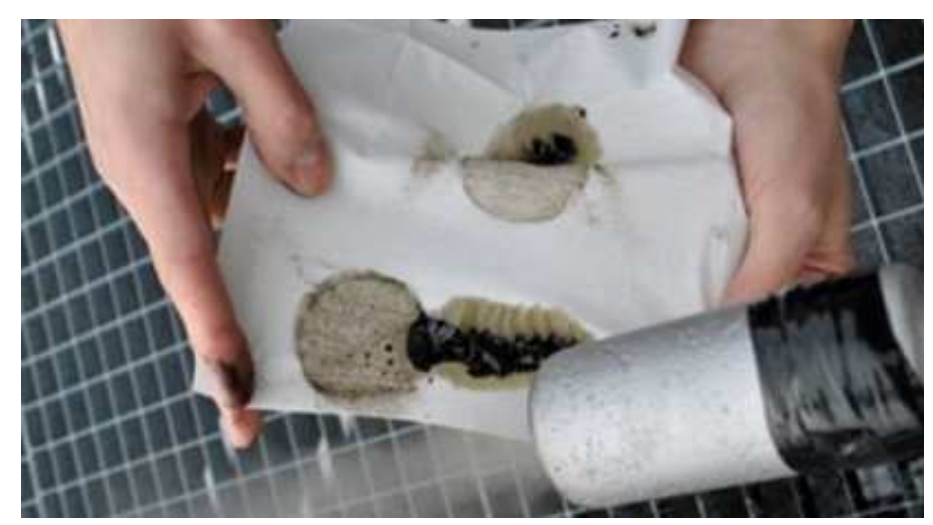

Rys. 2. Gaz drzewny wypływający z palnika generatora

Fig. 2. Wood gas from the generator burner

będą wpływały destrukcyjnie na pracę silnika spalinowego $[4,9]$. Substancja smolista, nazywana również dziegciem, stanowi mieszaninę węglowodorów, które tworzą się podczas pirolizy i częściowego spalania biomasy. W zależności od rodzaju biomasy poddawanej procesowi zgazowania, czynnika zgazowującego i temperatury, skład wytworzonego dziegciu może być różny. Aby gaz drzewny mógł zasilić silnik spalinowy, zawartość substancji smolistej nie może przekroczyć $100 \mathrm{mg} / \mathrm{m}_{\mathrm{n}}^{3}$ [15].

\section{Założenia techniczne układu kogeneracyjnego}

W celu prowadzenia analizy termodynamicznej układów kogeneracyjnych konieczna jest ilościowa ocena efektów energetycznych pracy układu. Najczęściej stosowane wskaźniki to:

- sprawność wytwarzania energii elektrycznej,

- sprawność mechaniczna silnika spalinowego,

- sprawność zgazowania,

- sprawność wytwarzania ciepła,

- sprawność całkowita układu kogeneracyjnego. 


\section{Sprawność elektryczna:}

$$
\eta_{e l}=\frac{N_{e l}}{\dot{m}_{b} \cdot W_{d b}},
$$

gdzie: $N_{e l}-$ moc elektryczna wytwarzana w skojarzeniu,

$\dot{m}_{b}$ - wydatek masowy biomasy,

$W_{d b}$ - wartość opałowa biomasy.

\section{Sprawność mechaniczna silnika spalinowego:}

$$
\eta_{m}=\frac{N_{m}}{\dot{m}_{b} \cdot W_{d b}}
$$

gdzie $N_{m}-$ moc mechaniczna silnika spalinowego.

\section{Sprawność zgazowania:}

$$
\eta_{z g}=\frac{\dot{n}_{g} \cdot W_{d g}}{\dot{m}_{b} \cdot W_{d b}}
$$

gdzie: $\dot{n}_{g}$ - wydatek objętościowy gazu drzewnego,

$W_{d g}$ - wartość opałowa gazu drzewnego.

Sprawność zgazowania jest to stosunek strumienia energii chemicznej gazu do strumienia energii chemicznej biomasy dostarczonej do zgazowania, jeżeli gaz drzewny zostanie ochłodzony do temperatury substratów. Sprawność zgazowania dla generatorów autotermicznych mieści się w zakresie 50-85\% [17].

\section{Sprawność wytwarzania ciepła:}

$$
\eta_{q}=\frac{\sum \dot{Q}}{\dot{m}_{b} \cdot W_{d b}}
$$

gdzie: $\sum \dot{Q}$ - suma mocy cieplnych odzyskanych z układu kogeneracyjnego.

\section{Sprawność całkowita:}

$$
\eta_{c}=E U F=\frac{N_{e l}+\sum \dot{Q}}{\dot{m}_{b} \cdot W_{d}},
$$

Jest to jeden z ważniejszych wskaźników określających efektywność konwersji energii chemicznej paliwa. Wielkość ta jest coraz częściej określana 
w literaturze jako wskaźnik wykorzystania energii chemicznej paliwa i oznaczana EUF (ang. Energy Utilization Factor) [18].

Układ skojarzonego wytwarzania energii elektrycznej i ciepła zasilany biomasą będzie się składał z następujących elementów (rys. 3.):

- gazogeneratora - wartość opałowa gazu drzewnego to ok. $5 \mathrm{MJ} / \mathrm{m}_{\mathrm{n}}{ }^{3}$, wsad biomasy stanowią zrębki drewna o wymiarach $3 \times 3 \mathrm{~cm}$,

- chłodnicy gazu drzewnego - jej zadaniem jest schłodzenie otrzymanego gazu od temperatury ok. $400-500^{\circ} \mathrm{C}$ do temperatury poniżej $40^{\circ} \mathrm{C}$, moc cieplna odzyskana to ok. $4 \mathrm{~kW}$,

- systemu oczyszczania gazu drzewnego - składa się z odpylacza inercyjnego oraz filtru z wełny mineralnej,

- silnika spalinowego - czterosuwowego, o zapłonie iskrowym i mocy mechanicznej ok. $7 \mathrm{KM}$,

- prądnicy elektrycznej - o mocy elektrycznej $4 \mathrm{~kW}$, połączonej z silnikiem spalinowym,

- wymiennika ciepła spalin - ochładzającego spaliny od temperatury nawet $700^{\circ} \mathrm{C}$; moc cieplna odzyskana to $5 \mathrm{~kW}$.

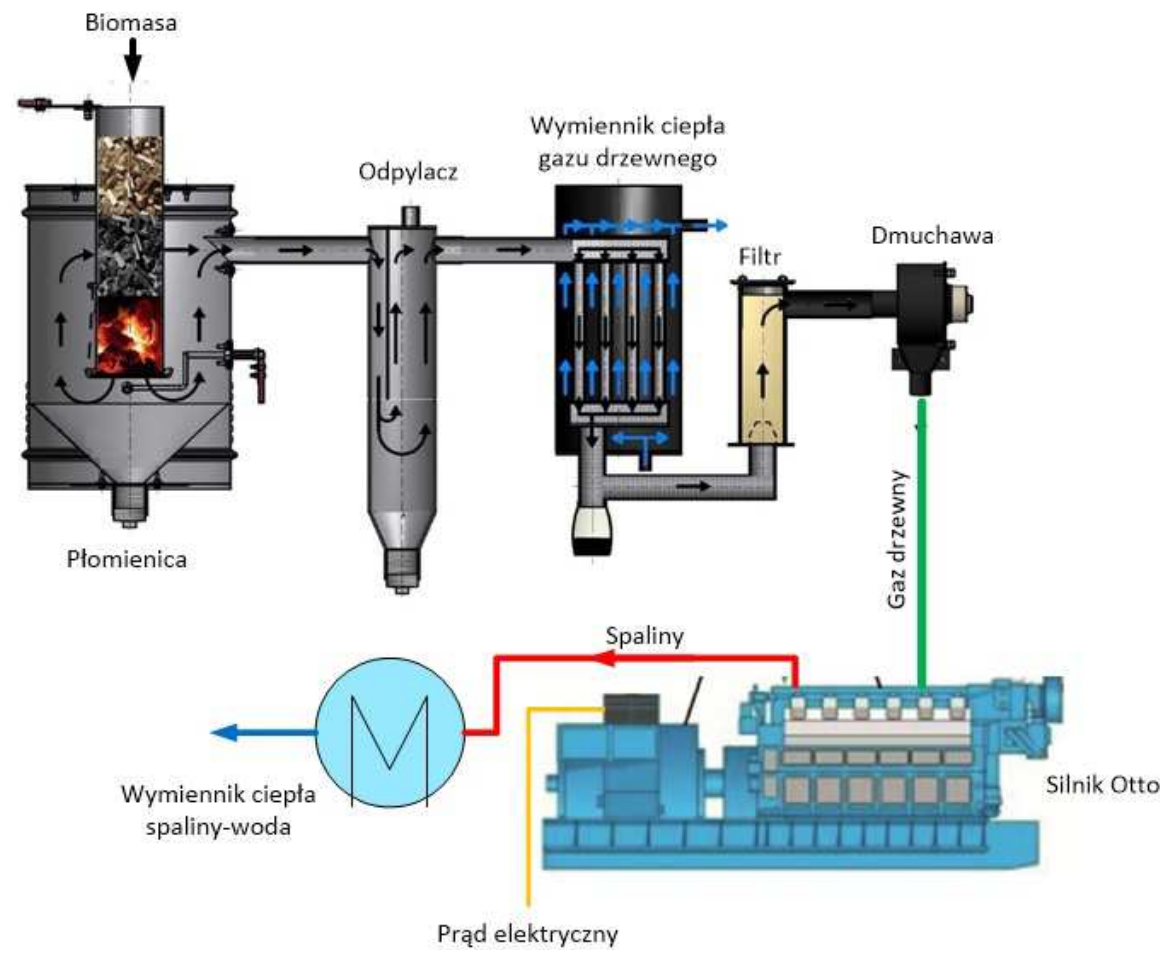

Rys. 3. Schemat układu skojarzonego wytwarzania energii elektrycznej i ciepła z gazu drzewnego

Fig. 3. Scheme of the system of combined production of electricity and heat from the wood gas 
W założeniach technicznych instalacji CHP zasilanej gazem drzewnym przyjęto dostępne na rynku elementy: wymiennik ciepła spaliny-woda, silnik oraz prądnicę. W układzie założono wykorzystanie prototypowego generatora gazu drzewnego, w którym zostanie zmodyfikowany system oczyszczania gazu drzewnego, oraz agregatu prądotwórczego o mocy elektrycznej $4 \mathrm{~kW}$. Agregaty tej mocy dostępne na rynku posiadają chłodzenie powietrzem, dlatego też nie jest możliwy odbiór ciepła z płaszcza silnika spalinowego. Założenia doboru silnika oraz wymiennika ciepła spaliny-woda zaprezentowano w tab. 4. Odzysk ciepła w rozpatrywanym przypadku następuje z dwóch źródeł - ochłodzenia gazu drzewnego powstałego z generatora gazu oraz ochłodzenia spalin silnika.

Tabela 4. Założenia doboru silnika

Table 4 . The assumptions of engine selection

\begin{tabular}{|l|c|c|}
\hline Strumień energii chemicznej paliwa & $\dot{m}_{b} \cdot W_{d}$ & $20 \mathrm{~kW}$ \\
\hline Sprawność zgazowania & $h_{z g}$ & $75 \%$ \\
\hline Sprawność mechaniczna silnika spalinowego & $h_{m}$ & $30 \%$ \\
\hline Sprawność generatora elektrycznego & $\eta_{e l}$ & $90 \%$ \\
\hline Moc elektryczna & $N_{e l}$ & $4 \mathrm{~kW}$ \\
\hline Sprawność elektryczna & $h_{e l}$ & $20 \%$ \\
\hline Moc cieplna chłodzenia gazu drzewnego & $N_{g}$ & $4 \mathrm{~kW}$ \\
\hline Moc cieplna chłodzenia spalin & $N_{s}$ & $5 \mathrm{~kW}$ \\
\hline Sprawność cieplna & $n_{q}$ & $45 \%$ \\
\hline Sprawność całkowita & $E U F$ & $65 \%$ \\
\hline
\end{tabular}

\section{Podsumowanie}

Wykorzystanie w silnikach spalinowych gazu drzewnego powstałego w procesie zgazowania biomasy zajmuje obecnie ważne miejsce pośród innych alternatywnych źródeł energii. Historyczne znaczenie omawianego układu do napędu pojazdów nie zostało rozwinięte i kontynuowane ze względu na wiele uwarunkowań technicznych, technologicznych czy też ekonomicznych. Okazuje się jednak, że otrzymywany w procesie zgazowania gaz drzewny zasilający układ CHP może stanowić konkurencyjne źródło energii elektrycznej i cieplnej wytwarzanej w kogeneracji. Będzie miało ono szczególne znaczenie w wytwarzaniu energii w systemach rozproszonych, niezależnych od dużych, scentralizowanych dostawców energii. Przykładem takiego odbiorcy - systemu rozproszonego - może być dom jednorodzinny. Układ CHP zasilany gazem drzewnym otrzymanym ze zgazowania biomasy uniezależnia dom jednorodzinny od zewnętrznych dostaw energii elektrycznej oraz ciepła. Urządzenie takie wytwarza energię elektryczną o mocy rzędu $4 \mathrm{~kW}$ oraz ciepło $9 \mathrm{~kW}$. Sprawność całkowitą układu CHP szacuje się na poziomie 65\%, co jest spowodowane brakiem odbioru ciepła od korpusu silnika, który dla tak małych jednostek (rzędu $7 \mathrm{KM}$ ) po- 
siada chłodzenie powietrzem. Pomimo istniejących utrudnień, m.in. konieczności usuwania powstałych substancji smolistych - dziegciu, zaproponowany układ może stanowić użyteczny i funkcjonalny element wyposażenia, pracujący jako główne lub dodatkowe źródło energii.

\section{Literatura}

[1] Ahrenfeldt J.: Characterization of biomass producer gas as fuel for stationary gas engines in combined heat and power production, $\mathrm{PhD}$ Dissertation, Technical University of Denmark, 2007.

[2] Basu P.: Biomass Gasification and Pyrolysis, Elsevier, Kidlington, Oxford 2010.

[3] Brandin J, Tunér M, Odenbrand I.: Small scale gasification: gas engine CHP for biofuels, Swedish Energy Agency Report, 2011, p. 137.

[4] Gil P.: Projekt techniczny układu kogeneracyjnego, praca inżynierska, Politechnika Rzeszowska, Rzeszów 2012.

[5] Gil P., Wilk J.: Zgazowanie biomasy w generatorze małej mocy, [w:] Ciepłownictwo, ogrzewnictwo, odnawialne źródła energii, pod red. W. Zimy, D. Talera, Wydawn. Politechniki Krakowskiej, Kraków 2013, s. 61-73.

[6] Gil P., Grosicki S., Wilk J.: Możliwości zastosowań metod oczyszczania gazu powstałego ze zgazowania biomasy w generatorze małej mocy, INSTAL, 12 (2013), $38-42$.

[7] Grosicki S., Gałek R., Gil P.: Wpływ temperatury zgazowania biomasy na zawartość metanu w gazie drzewnym. Zastosowanie analizy termodynamicznej do opisu zjawisk fizycznych i urządzeń energetycznych, pod red. M. Szewczyka, Oficyna Wydawnicza Politechniki Rzeszowskiej, Rzeszów 2014, s. 77-88.

[8] Hagos F.Y., Aziz A.R.A, Sulaiman S.A.: Trends of syngas as a fuel in internal combustion engines, Adv. Mech. Eng., article ID 401587, 2014.

[9] Herdin G., Robitschko R., Klausner J., Wagner M.: Erfahrungen von GEJ mit Holzgasanlagen, GE Jenbacher, 2002.

[10] Hetmańczyk I., Hepner W.: Gaz generatorowy - biopaliwo z tradycjami, Inżynieria Rolnicza, 4(139), t. 1(2012), 91-100.

[11] http://www.ekoautoilijat.fi.

[12] http://www.lowtechmagazine.com/2010/01/woodgas-cars.html.

[13] Jensen N., Werling J., Carlsen H., Henriksen U.: CHP from updraft gasifier and Stirling engine, Proc. 12th European Biomass Conference, ETA-Florence \& WIPMunich, pp. 726-729.

[14] Kitzer H., Pfeifer C., Hofbauer H.: Pressurized gasification of wwody biomass variation of parameter, Fuel Proc. Technol., 92 (2011), 908-914.

[15] Milne T.A., Evans R.J., Abatzoglou N.: Biomass gasifier tars: their nature, formation and conversion, National Renewable Energy Laboratory/TP-570-25357, Golden, Colorado 1998.

[16] Raman P., Ram N.K.: Performance analysis of an internal combustion engine operated on producer gas, in comparison with the performance of the natural gas and diesel engines, Energy, 63 (2013), 317-333. 
[17] Reed T.B., Das A.: Handbook of Biomass Downdraft Gasifier Engine System, Solar Energy Research Institute/SP-271-3022, Golden, Colorado 1988.

[18] Skorek J., Kalina J.: Gazowe układy kogeneracyjne, WNT, Warszawa 2006.

[19] Thapa R.K., Pfeifer C., Holvorsen B.M.: Modeling of reaction kinetics in bubbling fluidized bed biomass gasification reactor, Int. J. Energy Environment, 5 (2014), $35-44$.

\section{COMBINED HEAT AND POWER SYSTEM WITH COMBUSTION ENGINE FUELLED BY WOOD GAS}

\section{S u m m a r y}

The article contains a description of the concept of CHP unit with a four-stroke internal combustion engine powered by wood gas from biomass gasification. The methods of adaptation of internal combustion spark-ignition and compression-ignition engines to using wood gas were presented. Technical problems of engines powered by wood gas were also presented.

Keywords: gasification of biomass, CHP, combined production of electricity and heat, wood gas cleaning

DOI: $10.7862 / \mathrm{rm} .2015 .21$

Otrzymano/received: $11.01 .2015 \mathrm{r}$.

Zaakceptowano/accepted: 12.03.2015 r. 